\title{
Probiyotik Olarak Tanımlanan Yeni Mikroorganizmalar
}

\author{
Şeyma Delice Ürkmez, Ali Gücükoğlu \\ Ondokuz Mayls Üniversitesi Veteriner Fakültesi Besin Hijyeni ve Teknolojisi AD Samsun
}

Geliş Tarihi / Received: 04.01.2019, Kabul Tarihi / Accepted: 13.05.2019

\begin{abstract}
Özet: Tarih boyunca insanlar tarafından canlı mikroorganizmalar içeren bitkisel ve hayvansal orijinli fermente gıdalar tüketilmiştir. Geleneksel fermente gıdaların içerisinde "Probiyotik" olarak isimlendirilen doğal mikroorganizmalar, yeterli miktarda uygulandığında konakçıya yarar sağlayan canlı mikroorganizmalar olarak tanımlanır. Her geçen gün doğal kaynaklardan izole edilen ya da mevcut bakteri soylarından türetilen yeni bakteriler keşfedilmekte ve dolayısıyla bu bakterilerin probiyotik olarak değerlendirmelerinin yapılması ve güvenilirliklerinin derinlemesine araştırılması gerekmektedir. Detaylı inceleme gerektiren mikroorganizmaların son örneklerini Leuconostoc mesenteroides, Bacillus subtilis natto, Clostridium butyricum, Bacteroides xylanisolvens, Akkermansia muciniphila, Fruktofilik laktik asit bakterileri (FLAB) ve Faecalibacterium prausnitzii oluşturmaktadır. Bu derlemede probiyotik özellikleri yeni ortaya çıkarılan bazı mikroorganizmalar hakkında bilgi verilmesi amaçlanmıştır.
\end{abstract}

Anahtar kelimeler: Gida, Probiyotik bakteri, Yeni mikroorganizma

\section{Novel Microorganisms Accepted as Probiotics}

\begin{abstract}
Throughout history, fermented foods from vegetable and animal origin including live microorganisms have been consumed by humans. In traditional fermented foods, natural microorganisms, called probiotics, are defined as live microorganisms that benefit the host when administered in sufficient amounts. Everyday, new bacteria, which are isolated from natural sources or derived from the current strains of bacteria, are discovered and therefore probiotic assessments and reliability of these bacteria should be investigated in depth. Recent samples of microorganisms requiring detailed examination are Leuconostoc mesenteroides, Bacillus subtilis natto, Clostridium butyricum, Bacteroides xylanisolvens, Akkermansia muciniphila, Fructophilic lactic acid bacteria (FLAB) and Faecalibacterium prausnitzii. In this review, it is aimed to give information about some new microorganisms which have probiotic properties.
\end{abstract}

Key words: Food, Probiotic bacteria, New microorganism

\section{Giriș}

Antik çağlardan beri canlı mikroorganizmalar içeren gidalar insan beslenmesinin önemli bir bölümünü oluşturmuş ve özellikle fermente gıdalar, meyveler, meyve suları, hayvansal ürünler gibi doğal mikrobiyal içeriği olan gidalar tüketilmiştir. İnsanlar, bakterilerin varlığını bile bilmeden, onları birçok gıdanın üretimi ve saklanmasında etkin olarak kullanmışlardır [47]. Geleneksel fermente gıdaların içerisinde "Probiyotik" olarak isimlendirilen doğal mikroorganizmalar bulunmaktadır. Ancak unutmamak gerekir ki canlı bakteri içeren her fermente gıda aynı zamanda probiyotik özellikte değildir. Fermente gıdalar farklı sayı ve türde mikroorganizma içerdiklerinden bunların mikrobiyolojik kompozisyonu tamamen bilinmemekte veya üretim prosesinde kontrol edilememektedir [30]. International Scientific Association for Probiotics and Prebiotics (ISAPP) bu nedenle, geleneksel fermente gidalar için "canlı ve aktif bakteriyel kültürler içeren" terimini önermektedir. Probiyotikler, yeterli miktarda uygulandığında konakçıya yarar sağlayan canlı mikroorganizmalar olarak tanımlanır. Bu faydalar, araştırılan probiyotiklerin büyük çoğunluğunda; bağırsak geçişinin düzenlenmesi, patojenlerin rekabet dışı bırakılması ve spesifik kısa zincirli yağ asitleri üretimi gibi nispeten ortak mekanizmalar yoluyla sağlanmaktadır. Buna ek olarak, vitamin sentezi, enzimatik aktivite, bağırsak bariyer takviyesi ve kanserojenlerin nötrleştirilme mekanizmaları yer alır [10,30]. European Food Safety Authority (EFSA), biyolojik ajanların değerlendirilmesini basitleştirmek ve standardize etmek amacıyla mikroorganizmalar için genel risk değerlendirme yaklaşımı oluşturmaya yönelik Qualified Presumption of Safety (QPS) sistemini başlatmıştır. QPS yaklaşımı, düşük riskli mikroorganizmaların değerlendirilmesini basitleştirerek, yüksek risk potansiyeli olan ajanlara daha fazla odaklanmayı 
sağlamaktadır [36]. QPS kavramı, yem ve gıda üretiminde kullanılan tüm mikroorganizmalar için bir güvenlik değerlendirmesi oluşturmayı amaçlamaktadır. Etken, QPS listesindeki bir taksonomik birime açıkça bağlanabiliyorsa, gerekli güvenlik değerlendirme aşamaları varsa, bu taksonomik birim için listede belirtilir. Güvenilirlik özellikleri tam olarak anlaşılamayan mikroorganizmalar için tür veya izolat seviyesi üzerinde ayrı bir taksonomik sınıflandırma, potansiyel virülens, antibiyotik direnç genlerini ve bunların yatay aktarım yeteneklerini belirlemek için kapsamlı genetik dizilim analizi de dahil olmak üzere karakterizasyon analizleri yapılmaktadır [3].

\section{Probiyotik Olarak Tanımlanan Yeni Mikroorganizmalar}

\section{Leuconostoc mesenteroides}

L. mesenteroides, Laktobasiller grubunda Gram pozitif, sporsuz, katalaz, oksidaz ve PYR (L-pyrrolidonyl-b-naphthyla-mide) negatif, alfa veya non hemolitik koklardır [5,34]. Streptococcaceae ailesine dahil olup glikopeptidlere doğal dirençlidir [29,31]. L. mesenteroides, fakültatif anaerob olmasına rağmen mikroaerofilik koşullarda heterolaktik fermentasyon kabiliyetindedir [17]. Aynı zamanda sitrat1 diasetil ve asetoine dönüştürürken, sakarozu dekstran ve levana dönüştürür. Dekstranlar; kan plazma uzatıcıları, antikoagülan tedavi için heparin ikameleri, çeşitli kozmetik ürünlerin üretiminde kullanılmaktadır [33,35]. L. mesenteroides, birçok gidada fermantasyon işlemlerinin başlamasından sorumlu ve hatta çeșitli ekmek ve fermente süt ürünlerinde starter kültürler olarak kullanılmakta, geneneksel ve endüstriyel peynirlerin florasinda bulunabilmektedir $[12,16,48]$. EFSA L. mesenteroides'dan üretilen dekstran preparatının fırın ürünlerinde $\% 5$ 'e kadar kullanımının insan tüketimi için güvenli olduğunu bildirmiştir [2].

\section{Bacillus subtilis natto}

B. subtilis, toprakta, geviş getiren hayvanların ve insanların gastrointestinal kanalında bulunan Gram-pozitif, katalaz-pozitif, fakültatif anaerob mikroorganizmadır [38]. Japonya' da 1906 yılında keşfedilen $B$. subtilis natto, fermente edilmiş soya fasulyesi olan "natto" üretiminden sorumlu olup Japon diyetinde uzun süredir kullanılmaktadır. $B$. subtilis, gastrointestinal ve üriner sistem hastalıklarının tedavisinde antibiyotiklerden önce yaygın olarak kullanılan immünostimülatör ajanıdır. Sindirim sistemi üzerinden; IgM, IgG ve IgA spesifik antikorların ve interferonları indükleyen $\mathrm{CpG}$ dinükleotidlerin salgılanmasını sağlayarak genis spektrumlu bağışıklık aktivitesini uyarması nedeniyle alternatif bir ilaç olarak kullanılmıştır [13]. B. subtilis natto'ya güvenli kullanım öyküsü ve potansiyel vitamin prekürsörü özelliği nedeniyle EFSA tarafından QPS statüsü verilmiştir [20].

\section{Clostridium butyricum}

Gram pozitif, zorunlu anaerob, sporlu basil olan Clostridium butyricum, insan ve hayvan bağırsağ1nın kommensal bir bakterisidir. C. butyricum, yüksek miktarlarda bütirik asit üretme kapasitesine sahiptir $[27,42,45]$. EFSA C. butyricum CBM 588'in, yeni bir probiyotik olarak kullanılmasına izin vermiştir [4]. C. butyricum için bildirilen faydalı etkilerin başında SCFA (Short Chain Fatty Acids) üretimi ve lipit metabolizmasındaki etkinliği gelmektedir [49]. Yapılan çalıșmalarda etkenin, ülseratif kolit hastalarında kaşeksiyi önleme ve Helicobacter pylori için tedavi olan hastalarda oluşan yan etkilerin azaltılmasında olumlu etkileri saptanmıştır [50]. Oral yolla alındığında, C. butyricum sporları bağırsaklarda aktif hale geçerek bütirat ve asetat gibi çok miktarda kısa zincirli yağ asitleri üretir [44]. SCFA'lar bağırsak hücreleri için önemli bir enerji kaynağ1 oluşturur ve enterositler üzerinde proliferatif etkilere sahiptir. Ek olarak, SCFA'ların, kolonik inflamasyon üzerinde immün modülatör etkilere sahip olduğu belirtilmiştir. SCFA'lar epitel hücre kültürlerinde inflamatuar sitokin sekresyonunu baskılayarak, bağırsak mukozasının mikroorganizmaların varlığına karşı toleransını kolaylaştırmakta ve patojenlerin çoğalmasını kontrol etmektedir [28].

\section{Bacteroides xylanisolvens}

Chassard ve ark. [11] insan gastrointestinal kanalında, 6 ksilanolitik, Gram-negatif anaerobik çubuk izole etmişlerdir. Sonraki 16S rRNA analiziyle, elde edilen suşların Bacteroides cinsine ait olduğunu ve etkene ksilanın ayrıştırma özelliğine göre $B$. xylanisolvens ismini vermișlerdir. Bacteroides spp., insan kolon florasının baskın türlerinden olup, bağırsak mikrobiyatasının yaklașık \%30'unu olușturmak- 
tadır [46]. B. xylanisolvens DSM 23964 izolatının biyokimyasal özellikleri katalaz (-), indol (-) ve nişasta hidrolizi (-)'dir. Filogenetik analiz ve DNADNA hibridizasyonu ile $B$. xylanisolvens'in alt varyantı olarak sınıflandırılmıştır. B. xylanisolvens'in probiyotik olarak sinıflandırılmasina sebep olan en temel özelliği mide-bağırsak kanalında canlılığını koruyabilmesidir. B. xylanisolvens DSM 23964, stimüle edilmiş mide sıvısında 3 saat sonunda $\% 90$ oranında ve benzer şekilde stimüle edilmiş intestinal sıvıda 4 saat sonunda \%96 oranında canlılı̆̆ını koruyabildiği saptanmıştır. Ancak in vitro ortamda epitelyal hücrelere bağlanamaması probiyotik özelliklerin değerlendirilmesinde önemli bir dezavantajdır [51]. 2015 yılında B. xylanisolvens DSM 23964'ün fermente edilen pastörize süt ürünlerine probiyotik amaçlı katılması onaylanmış olup, etkenin probiyotik olarak kullanımı, pastörize süt ürünlerinin mayalanmasında başlangıç kültürü olarak sinırlandırılmıştır [21].

\section{Akkermansia muciniphila}

A. muciniphila başlangıçta zorunlu bir anaerob olarak sınıflandırılmıştır, fakat Bacteroides fragilis ve Bifidobacterium adolescentis gibi diğer anaerobik bağırsak kolonileriyle birlikte $A$. muciniphila'nın küçük miktarlarda oksijeni tolere edebildiği görülmüştür [40]. Yapılan araştırmalarda memeli bağırsak örneklerinde Akkermansia cinsine ait türler saptanmış olup, etkenin zebra balığg ve birmanya pitonu gibi diğer omurgalılarda da benzer türleri tespit edilmiştir $[15,43]$. Bununla birlikte $A$. muciniphila insanlarda meme dokusunda tespit edilmiş ve etkenin anne sütü ile bebeklere geçişi belirlenmiştir [14]. A. muciniphila, insan bağırsak mikrobiyatas1nın \%1-4'ünü oluşturmaktadır [18]. Akkermansia türlerinin patojenitesi ile ilgili genel endişeler vardir ancak A. muciniphila'nın herhangi bir spesifik hastalığa sebep olduğuna dair veriye rastlanılmamıştır [19]. A. muciniphila'nın $70{ }^{\circ} \mathrm{C}$ 'de 30 dakika 1s1 uygulamasından sonra etkenin obez ve diyabetik farelerde yăg kitle gelişimini, insülin direncini ve dislipidemiyi azalttığı görülmüştür. Bazı membran proteinleri, termal işlem sırasında bile Toll benzeri reseptör 2 ile stabilite ve etkileşim göstermiştir. $\mathrm{Bu}$ protein bağırsak bariyeri üzerine olumlu etkiler sağlamıştır [41]. Nispeten yeni tanımlanan tür olan $A$. muciniphila, Akkermansia cinsinin ilk tanımlanan taksonomik üyesidir ve gida endüstrisinde kullanım koşullarına ilişkin veriler yeterince bulunmadığından EFSA tarafindan yapılan QPS statüsüne göre herhangi bir değerlendirme yapılmamıştır [9].

\section{Faecalibacterium prausnitzii}

Fusobacterium prausnitzii, Faecalibacterium cinsine ve insan bağırsak mikrobiyotalarının komensal bakterisidir [37]. Gram pozitif, zorunlu anaerob olan F. prausnitzii, Clostridia sinıfina aittir. İnsanlarda toplam fekal bakteri florasının \%3-5'ini oluşturur [8,26,37]. Mikrobiyota içerisinde $F$. prausnitzii say1sındaki değişiklikler Crohn hastalığı ve depresif bozukluklar gibi birkaç gastrointestinal hastalık ile ilişkilendirilmiştir [32,37]. Etken konakta antiinflamatuar etki yaratmakta, bu da bazı hastalıklara bağ11 disbiyozisin dengelenmesinde kullanılabileceğini göstermektedir [32,37]. F. prausnitzii EFSA tarafindan henüz QPS listesine dahil edilmemiştir [8].

\section{Fruktofilik Laktik Asit Bakterileri}

Fruktofilik laktik asit bakterileri (FLAB), Laktik asit bakterileri (LAB) içerisinde bir alt grup oluşturur. FLAB tercihen bir substrat olarak fruktoz kullanır, glikozu tam olarak fermente edemez ve ortamda bulunan piruvat, oksijen ve fruktoz varlığında gelişme ve çoğalmaları önemli ölçüde artar. Etken daha çok; çiçekler, meyveler, şarap ve kakao çekirdeği gibi fermente gidalar ve böceklerin gastrointestinal sisteminde bulunur $[23,24]$. FLAB grubu bakterilerin siniflandirilmasinda, Fructobacillus spp. ve Lactobacillus spp. cinsleri yer almaktadır [22]. Fructobacillus beş türden oluşur: F. fructosus, $F$. pseudoficulneus, F. ficulneus, F. durionis ve F. tropaeoli [25]. F. fructosus ve F. pseudoficulneus, doğal kaynaklarda en s1k tespit edilen türlerdir $[1,24]$. Lactobacillus cinsinden FLAB üyeleri L. kunkeei, L. apinorum ve L. florum' dur [39]. Yapılan çalışmalarda, gıdayla alınan ve isı ile inaktif hale getirilmiş L. kunkeei'nin bağırsak peristaltiğini $\operatorname{artırdığ~}$ immünoglobulin A üretimi gibi immunitede yarar11 etkilere sahip olduğu saptanmıştır. Bu nedenle, B. xylanisolvens'lerde olduğu gibi, L. kunkeei'nin, g1da endüstrisinde 1 sıl işleme tabi tutulmuş formda kullanılabileceği düşünülmektedir. G1da endüstrisinde çok yaygın olarak kullanılan LAB ile olan yakın filogenetik ilişkileri, EFSA tarafından QPS listesine dahil edilmesi olasılığını gündeme getirmiştir. Ancak etkeni genetik karakterizasyonunda laktik asit bakterilerinden tam olarak ayırmak ve fermente 
gıdaların üretimi ile arasındaki ilişkiyi anlamak için daha fazla bilimsel veriye ihtiyaç vardır [6,7].

\section{Sonuç}

Dünyada hızla büyüyen gıda pazarı dikkate alındığında probiyotik olarak önerilen yeni bakteriler ve bunları içeren yeni gıdalar ilgi çekmektedir. Yeni probiyotik adaylar için, gıdalarda kullanımları ile ilgili yeterli deneyim olmadığından bu yeni türlerin piyasaya sürülmesi güvenilirlik endişelerini de beraberinde getirmektedir. Bu nedenle bazı ülke ve kuruluşlar probiyotiklerle ilgili çeşitli yasal düzenlemeler geliştirmişlerdir. Mevcut farklı düzenlemelerin en önemli ortak noktası bu yeni türlerin piyasaya sürülmesinden önce olası bir sağl1k tehdidinin ortadan kaldırılmasıdır. Bu derlemede bahsi geçen Leuconostoc mesenteroides, Bacillus subtilis natto, Clostridium butyricum ve Bacteroides xylanisolvens'e EFSA tarafindan probiyotik onayı verilmiştir. Diğer adaylardan $A$. muciniphila, FLAB ve $F$. prausnitzii için ise eldeki veriler umut verici olarak nitelendirilmiştir ve söz konusu türler halen EFSA tarafindan bilimsel risk değerlendirme aşamasındadır. Değerlendirilen potansiyel probiyotiklerin, gelecekte gida endüstrisinde yeni gıdalara dahil edilebilecek bakteriler olabileceği düşünülmektedir.

\section{Kaynaklar}

1. Alcantara-Hernandez RJ, Rodriguez-Alvarez JA, ValenzuelaEncinas C, Gutierrez-Miceli FA, Castanon-Gonzalez H, Marsch R, Ayora-Talavera T, Dendooven L, (2010). The bacterial community in 'taberna' a traditional beverage of Southern Mexico. Lett Appl Microbiol. 51, 558-563.

2. Anonim, (2001). European Commission. E. Commission: 2001/122/EC. Commission Decision of 30 January 2001 on Authorising the Placing on the Market of a Dextran Preparation Produced by Leuconostoc mesenteroides as a Novel Food Ingredient in Bakery Products under Regulation (EC) No 258/97 of the European Parliament and of the Council (Notified Under Document Number C(2001) 174). Erişim adresi; https://eur-lex.europa.eu/legal-content/EN/TXT/PDF/?uri $=$ CELEX:32001D0122\&from=HR, Erişim tarihi: 01.12.2018.

3. Anonim, (2007). Introduction of a Qualified Presumption of Safety (QPS) Approach for Assessment of Selected Microorganisms Referred to EFSA - Opinion of the Scientific Committee. Erişim adresi: https://efsa.onlinelibrary.wiley.com/ doi/epdf/10.2903/j.efsa.2007.587, Erişim tarihi: 30.11.2018

4. Anonim, (2014). European Commission. E. Commission: 2014/907/EU. Commission Implementing Decision of 11 December 2014 Authorising the Placing on the Market of Clostridium butyricum (CBM 588) as a Novel Food Ingredient under Regulation (EC) No 258/97 of the European Parliament and of the Council (Notified Under Document C(2014) 9345). Erişim adresi: https://eur-lex.europa.eu/legal-content/EN/ TXT/PDF/?uri=CELEX:32014D0907\&from=EN, Erişim tarihi: 01.12.2018.

5. Arias AC, Murray BE, (2010). Enterococcus species, Streptococcus bovis group, and Leuconostoc species. Mandell GL, Bennett JE, Dolin R. eds. Principles and practice of Infectious Diseases. 7th ed. Churchill Livingstone Elsevier Inc, Philadelphia, USA. p.2643-2653.

6. Asama T, Arima TH, Gomi T, Keishi T, Tani H, Kimura Y, Tatefuji T, Hashimoto K, (2015). Lactobacillus kunkeei YB38 from honeybee products enhances IgA production in healthy adults. J Appl Microbiol. 119, 818-826.

7. Asama T, Kimura Y, Kono T, Tatefuji T, Hashimoto K, Benno Y, (2016). Effects of heat-killed Lactobacillus kunkeei YB38 on human intestinal environment and bowel movement: a pilot study. Benef Microbes. 7, 337-344.

8. Breyner NM, Michon C, de Sousa CS, Vilas Boas PB, Chain F, Azevedo V, Langella P, Chatel JM, (2017). Microbial AntiInflammatory Molecule (MAM) from Faecalibacterium prausnitzii shows a protective effect on DNBS and DSSinduced colitis model in mice through inhibition of NF-kappaB pathway. Front Microbiol. 8, 114.

9. Brodmann T, Endo A, Gueimonde M, Vinderola G, Kneifel W, De Vos WM, Salminen S, Gomez-Gallego C, (2017). Safety of Novel Microbes for Human Consumption: Practical Examples of Assessment in the European Union. Front Microbiol. 8, 1725.

10. Cammarota G, Ianiro G, Bibbo S, Gasbarrini A, (2014). Gut microbiota modulation: probiotics, antibiotics or fecal microbiota transplantation? Intern Emerg Med. 9, 365-373.

11. Chassard C, Delmas E, Lawson PA, Bernalier-Donadille A, (2008). Bacteroides xylanisolvens sp. nov., a xylan-degrading bacterium isolated from human faeces. Int J Syst Evol Microbiol. 58(Pt 4), 1008-1013.

12. Cibik R, Lepage E, Talliez P, (2000). Molecular diversity of leuconostoc mesenteroides and leuconostoc citreum isolated from traditional french cheeses as revealed by RAPD fingerprinting, $16 S$ rDNA sequencing and $16 S$ rDNA fragment amplification. Syst Appl Microbiol. 23, 267-278.

13. Ciprandi G, Scordamaglia A, Venuti D, Caria M, Canonica GW, (1986). In vitro effects of Bacillus subtilis on the immune response. Chemioterapia. 5, 404-407.

14. Collado MC, Laitinen K, Salminen S, Isolauri E, (2012). Maternal weight and excessive weight gain during pregnancy modify the immunomodulatory potential of breast milk. Pediatr Res. 72, 77-85.

15. Costello EK, Gordon JI, Secor SM, Knight R, (2010). Postprandial remodeling of the gut microbiota in Burmese pythons. ISME J. 4, 1375-1385.

16. D'Angelo L, Cicotello J, Zago M, Guglielmotti D, Quiberoni A, Suarez V, (2017). Leuconostoc strains isolated fromdairy products: response against food stress conditions. Food Microbiol. $66,28-39$.

17. Demoss RD, Bard RC, Gunsalus IC, (1951). The mechanism of heterolactic fermentation: a new route of ethanol formation. $\mathrm{J}$ Bacteriol. 62, 499-511.

18. Derrien M, Collado MC, Ben-Amor K, Salminen S, De Vos WM, (2008). The mucin degrader Akkermansia muciniphila is an abundant resident of the human intestinal tract. Appl Environ Microbiol. 74, 1646-1648. 
19. Derrien M, van Passel MWJ, van de Bovenkamp JHB, Schipper RG, de Vos WM, Dekker J, (2010). Mucin-bacterial interactions in the human oral cavity and digestive tract. Gut Microbes. 1, 254-268.

20. EFSA Panel on Biological Hazards, (2010). Scientific Opinion on the maintenance of the list of QPS biological agents intentionally added to food and feed. EFSA J. 8, 1-56.

21. EFSA Panel on Dietetic Products, Nutrition and Allergies, (2015). Scientific Opinion on the safety of heat-treated milk products fermented with Bacteroides xylanisolvens DSM 23964 ' as a novel food. EFSA J. 13, 1-18.

22. Endo A, Futagawa-Endo Y, Dicks LM (2009). Isolation and characterization of fructophilic lactic acid bacteria from fructose-rich niches. Syst Appl Microbiol. 32, 593-600.

23. Endo A, Irisawa T, Futagawa-Endo Y, Takano K, du Toit M, Okada S, Dicks LM, (2012a). Characterization and emended description of Lactobacillus kunkeei as a fructophilic lactic acid bacterium. Int J Syst Evol Microbiol. 62, 500-504.

24. Endo A, (2012b). Fructophilic lactic acid bacteria inhabit fructose-rich niches in nature. Microb Ecol Health Dis. 23, 6-12.

25. Endo A, Tanizawa Y, Tanaka N, Maeno S, Kumar H, Shiwa Y, Okada S, Yoshikawa H, Dicks L, Nakagawa J, Arita M, (2015). Comparative genomics of Fructobacillus spp. and Leuconostoc spp. reveals niche-specific evolution of Fructobacillus spp. BMC Genomics. 16, 1117.

26. Foditsch C, Santos TM, Teixeira AG, Pereira RV, Dias JM, Gaeta N, Bicalho RC, (2014). Isolation and characterization of Faecalibacteriumprausnitzii from calves and piglets. PLoS ONE. 9, e116465

27. Ghoddusi HB, Sherburn R, (2010). Preliminary study on the isolation of Clostridium butyricum strains from natural sources in the UK and screening the isolates for presence of the type E botulinal toxin gene. Int J Food Microbiol. 142, 202-206.

28. Hamer HM, Jonkers D, Venema K, Vanhoutvin S, Troost FJ, Brummer RJ, (2008). The role of butyrate on colonic function. Aliment Pharmacol Ther. 27, 104-119.

29. Handweger S, Horowitz H, Coburn Kenneth, Kolokathis A, Wormser PG, (1990). Infection due to Leuconostoc species; Six cases and Review. Clin Infect Dis. 12, 602-610.

30. Hill C, Guarner F, Reid G, Gibson GR, Merenstein DJ, Pot B, Morelli L, Canani RB, Flint HJ, Salminen S, Calder PC, Sanders ME, (2014). The International Scientific Association for Probiotics and Prebiotics consensus statement on the scope and appropriate use of the term probiotic. Nat Rev Gastroenterol Hepatol. 11, 506-514.

31. Ishiyama K, Yamazaki H, Senda Y, Yamauchi H, Nakao S, (2011). Leuconostoc bacteremia in tree patients with malignancies. J Infect Chemother. 17, 412-418.

32. Jiang H, Ling Z, Zhang Y, Mao H, Ma Z, Yin Y, Wang W, Tang W, Tan Z, Shi J, Li L, Ruan B, (2015). Altered fecal microbiota composition in patients with major depressive disorder. Brain Behav Immun. 48, 186-194.

33. Kim D, Day DF, (1994). A new process for the production of clinical dextran by mixed-culture fermentation of Lipomyces starkeyi and Leuconostoc mesenteroides. Enzyme Microb Technol. 16, 844-848.

34. Koneman EW, Allen SD, Janda WM, Schreckenberger PC, Winn WC Jr, eds., (1997). Koneman's Color Atlas and Textbook of Diagnostic Microbiology. Fifth edition. Philadelphia: Lippincott, p.577-650.
35. Leathers TD, Hayman GT, Cote GL, (1995). Rapid Screening of Leuconostoc mesenteroides Mutants for Elevated Proportions of Alternan to Dextran. Current Microbiol. 31, 19-22.

36. Leuschner RGK, Robinson TP, Hugas M, Cocconcelli PS, Richard- Forget F, Klein G, Licht TR, Nguyen-The C, Querol A, Richardson M, Suarez JE, Thrane U, Vlak JM, von Wright A, (2010). Qualified presumption of safety (QPS): a generic risk assessment approach for biological agents notified to the European Food Safety Authority (EFSA). Trends Food Sci Technol. 21, 425-435.

37. Miquel S, Martin R, Rossi O, Bermudez-Humaran LG, Chatel JM, Sokol H, Thomas M, Wells JM, Langella P, (2013). Faecalibacteriumprausnitzii and human intestinal health. Curr Opin Microbiol. 16, 255-261.

38. Nakano MM, Zuber P, (1998). Anaerobic growth of a "strict aerobe" (Bacillus subtilis). Annu Rev Microbiol. 52, 165-90.

39. Neveling DP, Endo A, Dicks LM, (2012). Fructophilic Lactobacillus kunkeei and Lactobacillus brevis isolated from fresh flowers, bees and bee-hives. Curr Microbiol. 65, 507-515.

40. Ouwerkerk JP, van der Ark KC, Davids M, Claassens NJ, Robert Finestra T, de Vos WM, Belzer C, (2016). Adaptation of Akkermansia muciniphila to the oxic-anoxic interface of the mucus layer. Appl Environ Microbiol. 82, 6983-6993.

41. Plovier H, Everard A, Druart C, Depommie, C, Van Hul M, Geurts L, Chilloux J, Ottman N, Duparc T, Lichtenstein L, Myridakis A, Delzenne NM, Klievink J, Bhattacharjee A, van der Ark KC, Aalvink S, Martinez LO, Dumas ME, Maiter D, Loumaye A, Hermans MP, Thissen JP, Belzer C, de Vos WM, Cani PD, (2017). A purified membrane protein from Akkermansia muciniphila or the pasteurized bacterium improves metabolism in obese and diabetic mice. Nat Med. 23, 107-113.

42. Rainey FA, (2009). Genus I. Clostridium Prazmowski 1880. Vos P, Garrity G, Jones D, Krieg NR, Ludwig W, Rainey FA, eds. Bergey's Manual of Systematic Bacteriol: volume 3 The Firmicutes. 9th ed., Springer, New-York. p.739-740

43. Roeselers G, Mittge EK, Stephens WZ, Parichy DM, Cavanaugh CM, Guillemin K, Rawls JF, (2011). Evidence for a core gut microbiota in the zebrafish. ISME J. 5, 1595-1608.

44. Sato R, Tanaka M, (1997). Intestinal distribution and intraluminal localization of orally administered Clostridium butyricum in rats. Microbiol Immunol. 41, 665-671.

45. Schlegel HG (1993). General Microbiology. Seventh edition. Cambridge: CU Press, p.193-233.

46. Sears CL, (2005). A dynamic partnership: celebrating our gut flora. Anaerobe. 11, 247-251.

47. Selhub EM, Logan AC, Bested AC, (2014). Fermented foods, microbiota, and mental health:ancient practice meets nutritional psychiatry.J Physiol Anthropol. 33.

48. Server-Busson C, Foucaud C, Leveau JY, (1999). Selection of Dairy Leuconostoc Isolates for Important Technological Properties. J Dairy Res. 66, 245-56.

49. Shang H, Sun J, Chen YQ, (2016). Clostridium butyricum CGMCC0313.1 modulates lipid profile, insulin resistance and colon homeostasis in obese mice. PLoS ONE. 11, e0154373.

50. Shimbo I, Yamaguchi T, Odaka T, Nakajima K, Koide A, Koyama H, Saisho H, (2005). Effect of Clostridium butyricum on fecal flora in Helicobacter pylori eradication therapy. World J Gastroenterol. 11,7520-7524.

51. Ulsemer P, Toutounian K, Schmidt J, Karsten U, Goletz S, (2012). Preliminary safety evaluation of a new Bacteroides xylanisolvens isolate. Appl Environ Microbiol. 78, 528-535. 